\title{
Development of an item bank for food parenting practices based on published instruments and reports from Canadian and US parents
}

Teresia M. O'Connor ${ }^{1}$, Truc Pham ${ }^{1}$, Allison W. Watts ${ }^{2}$, Andrew W. Tu ${ }^{3}$, Sheryl O. Hughes ${ }^{1}$,

Mark R. Beauchamp ${ }^{4}$, Tom Baranowski ${ }^{1}$, Louise C. Mâsse ${ }^{3}$

${ }^{1}$ USDA/ARS Children's Nutrition Research Center, Baylor College of Medicine, Houston, TX, USA

${ }^{2}$ Division of Epidemiology and Community Health, School of Public Health, University of Minnesota, Minneapolis, MN, USA

${ }^{3}$ Child \& Family Research Institute, School of Population and Public Health, University of British Columbia, Vancouver, BC, Canada

${ }^{4}$ School of Kinesiology, University of British Columbia, Vancouver, BC, Canada

\author{
Corresponding author: \\ Teresia O’Connor, MD, MPH \\ Address: \\ Children's Nutrition Research Center \\ 1100 Bates St \\ Houston, TX 77030 \\ teresiao@bcm.edu
}

Keywords: parenting practices, food, nutrition, child, item bank, systematic review, parents Abbreviations: US: United States, NIH: National Institutes of Health, IRM: Item Response Modeling, CIHR: Canadian Institute of Health Research 


\section{Abstract}

2 Research to understand how parents influence their children's dietary intake and eating behaviors

3 has expanded in the past decades and a growing number of instruments are available to assess

4 food parenting practices. Unfortunately, there is no consensus on how constructs should be

5 defined or operationalized, making comparison of results across studies difficult. The aim of this

6 study was to develop a food parenting practice item bank with items from published scales and

7 supplement with parenting practices that parents report using. Items from published scales were

8 identified from two published systematic reviews along with an additional systematic review

9 conducted for this study. Parents $(n=135)$ with children 5-12 years old from the US and Canada,

10 stratified to represent the demographic distribution of each country, were recruited to participate

11 in an online semi-qualitative survey on food parenting. Published items and parent responses

12 were coded using the same framework to reduce the number of items into representative

13 concepts using a binning and winnowing process. The literature contributed 1,392 items and

14 parents contributed 1,985 items, which were reduced to 262 different food parenting concepts

15 (26\% exclusive from literature, $12 \%$ exclusive from parents, and $62 \%$ represented in both). Food

16 parenting practices related to 'Structure of Food Environment' and 'Behavioral and Educational'

17 were emphasized more by parent responses, while practices related to 'Consistency of Feeding

18 Environment' and 'Emotional Regulation' were more represented among published items. The

19 resulting food parenting item bank should next be calibrated with item response modeling for 20 scientists to use in the future. 


\section{INTRODUCTION}

Childhood obesity continues to be a public health concern in much of the world, and children's dietary intake is an important contributing factor to the development of obesity. Many children do not meet dietary guideline recommendations; instead their intake patterns increase their risk of developing obesity, diabetes, heart disease and some cancers (Ogata \& Hayes, 2014; US Department of Health and Human Services, US Department of Agriculture, Dietary Advisory Guidelines Committee, 2005). In the United States (US), only about 3\% of 2-18 year old children met the 2005 US Dietary Guideline (US Department of Health and Human Services, US Department of Agriculture, Dietary Advisory Guidelines Committee, 2005) limits for energy from solid fats and added sugar (Kirkpatrick, Dodd, Reedy, \& Kreb-Smith, 2012), while 15\% and $0.5 \%$ met the recommended total fruit and vegetable intakes, respectively (Kirkpatrick et al., 2012). Moreover, merely 10-37\% of US children (Guenther, Dodd, Reedy, \& Krebs-Smith, 2006) and about 30-40\% of Canadian children (Garriguet D., 2004) consumed at least five servings of fruit and vegetables per day (lower than the 2005 US Dietary Guidelines).

Recommendations by the American Heart Association and the American Academy of Pediatrics state that prevention and treatment of childhood obesity should be targeted at the family level (Barlow, 2007; Daniels et al., 2005), with a growing interest in targeting and understanding how parenting can promote healthier lifestyle behaviors in children. From this, a large body of studies has evolved to assess the impact of food parenting practices on children's food consumption. Parenting practices are the actions parents engage in to influence their child's corresponding behavior in a specific context, such as eating (Darling \& Steinberg, 1993). These practices differ from parenting styles, which represent the emotional climate that a parent establishes between him/herself and their child (Darling \& Steinberg, 1993). 
With the growing interest in food parenting practices, numerous instruments have been 45 developed to measure these practices. Two recent reviews identified 57 unique food parenting 46 practice instruments for children 2 to 12 years old (A. Vaughn, Tabak, Bryant, \& Ward, 2013) 47 and 21 unique food parenting practices for children 0 to 5 years old (de Lauzon-Guillain et al., 48 2012). The large number of available instruments from different fields of study (e.g. nutrition, 49 psychology, and medicine) has led to inconsistency in defining food parenting constructs. There 50 is currently no agreement as to which parenting constructs or dimensions should be assessed by 51 these instruments or how a specific dimension should be operationalized. What has resulted is a 52 field in which different investigators will use a similar item to assess constructs with different 53 labels. For example, versions of the item "Offer/Reward your child with sweets/desserts if they 54 eat (meal or healthy option)" have been used in several measures in which the authors classified 55 it into a different dimension, including instrumental feeding (Wardle, Sanderson, Guthrie, 56 Rapoport, \& Plomin, 2002), parent-centered feeding (Hughes, Power, Orlet Fisher, Mueller, \& 57 Nicklas, 2005), practical methods (O’Connor et al., 2010), pushing the child to eat more 58 (Baughcum et al., 2001), and use of rewards (Hendy, Williams, Camise, Eckman, \& Hedemann, 59 2009). As a result, it is not always clear what these dimensions mean, how they relate, or 60 whether they can be compared across studies. In addition, a wide range of approaches have been 61 used to develop items for food parenting practice instruments and authors have inconsistently 62 reported on the psychometric properties of resulting scales(de Lauzon-Guillain et al., 2012; A. 63 Vaughn et al., 2013), making it even more difficult to compare or aggregate results across 64 studies.

65 One approach to address these measurement concerns is to utilize the framework of the 66 NIH PROMIS initiative for developing a repository of calibrated items (i.e., an item bank) with 
67 Item Response Modeling (IRM) which has improved the assessment of patient reported

68 outcomes (see www.nihpromis.org/ NIH PROMIS initiative) (Revicki \& Cella, 1997). However,

69 such methods have received little attention in the behavioural sciences (Mâsse, Wilson,

70 Baranowski, \& Nebeling, 2006) or food parenting research (Masse \& Watts, 2013). IRM item

71 banking provides an ideal platform for creating a repository of items in which only

72 psychometrically-valid items are ultimately included in the item bank. Most importantly, IRM

73 item banking provides the platform for using Computerized Adaptive Testing (CAT) which

74 allows scientists the flexibility of selecting which items are included as relevant in a given study

75 while maintaining the ability to compare results across studies, yet reducing participant

76 burden(Mâsse et al., 2006). The initial step in developing a food parenting practice IRM item

77 bank is to populate the bank with published items that can be further assessed in planned future

78 studies. These items should be "binned" or classified into the appropriate latent construct to

79 represent the dimensions of the conceptual framework (DeWalt, Rothrock, Yount, \& Stone, 80 2007). The pool of items should then be reduced into representative items using a winnowing

81 process to eliminate redundancy, rewritten to eliminate double-barrelled items, and modified to

82 clarify poorly worded items. Finally, new items should be generated to cover missing constructs

83 or concepts less well represented.

84 The specific aims of this study were to a) populate a food parenting practice item bank 85 with published items, b) supplement the published items with parenting practices that parents 86 report using to get their child to eat healthy (that are/were not included in the published 87 measures), and c) examine the extent to which the parent reported food parenting practices were 88 incorporated in published instruments. The ultimate goal is to develop an item bank of food 
To develop an item bank of food parenting practices for elementary school aged children

93 (5-12 years old), published instruments were systematically identified and scales and items were 94 retrieved. To ensure our final item bank included those parenting practices that parents reported 95 using, data were also collected on Canadian and US parents to determine what practices they 96 commonly used to get their 5 to 12 year old children to eat healthily. After comparison with what 97 was retrieved from the literature, the parent reported practices were used to supplement the 98 published items to create a more complete item bank. This research protocol was approved by 99 the Research Ethics Board at the University of British Columbia and received Institutional 100 Review Board approval from Baylor College of Medicine.

101 Identifying published instruments

Published food parenting practice (food parenting practice) instruments were identified

103 by: 1) assessing published systematic reviews for related articles, 2) conducting an additional 104 systematic review to include recent studies, and 3) reviewing reference lists from retrieved 105 articles to identify publications not included in the systematic reviews (Figure 1). The process for 106 developing the nutrition-related parenting practice item bank was conducted in parallel with 107 identifying physical activity related parenting practice measures (manuscript submitted).

108 Therefore, instruments were also identified that included both physical activity and nutrition 109 items.

110 Published systematic reviews 
Recently published systematic reviews of food parenting practice instruments were used

112 as a starting point to identify measures (de Lauzon-Guillain et al., 2012; A. Vaughn et al., 2013).

113 All articles and instruments from these reviews were obtained and evaluated to determine their

114 inclusion in the database. If the article did not provide the complete or original measure, the

115 original authors were contacted in attempts to obtain the items.

Articles were included in the database if they utilized measures with: a) at least one scale on parenting or caregiver behaviors related to children's eating, nutrition, or food intake; b) more than one item; c) parent, child, or proxy report; d) an English version; and e) a target population that included children between 2 to 16 years old in part or whole (in order to be comprehensive and identify those instruments within our targeted age range of 5-12 years old, such that instruments for 2-5 year olds or 10-16 years old were also included). A broad age range was included for the published articles to capture instruments assessing food parenting from preschool through adolescents to increase the pool of items. Articles that described the development or evaluation of a measure, or the modification or addition of items, structure, or psychometrics to an existing measure were also included.

Exclusion criteria were measures that: a) focused solely on breastfeeding, age of introduction of specific food groups, direct observation of behaviors, or children with clinical pathologies or disease; b) assessed only parenting attitudes or styles; or c) assessed only child determinants of behavior, child eating behaviors, food expenditure and time use surveys, children's taste or food preferences, or body image perceptions. Instruments whose items were not published and were not obtained from the authors after multiple requests were excluded. Articles that presented only validity data among children less than two years old, or used an existing instruments without any modifications or new psychometric data were also excluded. 
Additional systematic review

An additional systematic review was conducted by the authors to identify recent articles

\section{Developing item bank of published instruments}

\section{Data extraction}

To develop a repository of existing food parenting practice items, data were extracted from each article using electronic forms in Microsoft Access. A formal data extraction protocol was developed and pilot tested to ensure consistency and accuracy in the appraisal of each article. Data extracted included: general information about the article and measurement tool including article reference, country, administration mode, measurement structure (uni- or multidimensional), and whether the study was linked to any previous measures (supplemental 
158 measure (whether the measure was developed based on theory or qualitative data); psychometric 159 information for the whole instrument; and individual factor levels based on the COSMIN 160 taxonomy (Mokkink et al., ). This included information about the structure of the measure, 161 reliability (alpha levels, test-retest), and validity (content, convergent, and criterion, as well as 162 structural and cross-cultural); and information regarding the measurement instrument (e.g. 163 question stems, instructions, the response options, the actual item and its original structural 164 construct, whether the item was modified during development of the measure, and the primary 165 food type the item refers to).

\section{Reduction procedures to consolidate similar items}

167 To consolidate the item bank using a winnowing process, all items were independently 168 reviewed and coded by two research staff (TP and AWW) with 19 primary food parenting 169 practice categories independent of their original factor structure or other published category. The 170 two coders compared all their initial discrepancies and all codes were triangulated by discussion 171 with at least one of the leaders of the research team (TMO or LCM) and discrepancies were 172 discussed and iteratively reviews among all four members (TP, AWW, TMO, and LCM). Final 173 codes were reached through consensus by all four members. The coding scheme was based on a 174 comprehensive review of all published constructs and was intended to be used as a tool to 175 categorize and reduce similar items rather than as a final conceptual model (Table 1).

Table 1here

Once all items were coded to one of the 19 food parenting practice categories, duplicate 179 items were removed and very similarly worded items in each category were collapsed together 
180 (i.e. "I say something positive about the food my child is eating during dinner" (Murashima,

181 Hoerr, Hughes, \& Kaplowitz, 2011) and "Say something positive about the food the child is

182 eating during dinner" (Hughes et al., 2006)). Next, items in each category that covered similar concepts (i.e. "I say something positive about the food my child is eating during dinner" and "I say something nice about the foods my child eats") were further collapsed and a "representative item' was developed (i.e. "I say something positive about the food my child eats [./during dinner.]"). The development of representative items within each category was initiated by one research staff and reviewed by a second staff. Discrepancies were reviewed by two research team members iteratively until all four members agreed on the reduced list/wording of representative items.

\section{Semi-qualitative study}

In order to generate new items to cover potentially missing constructs or concepts less well represented in the published literature, we conducted semi-qualitative surveys with parents of 5 to 12 year old children in the United States and Canada. This allowed us to compare parent reported concepts to items published in the literature.

Parents of 5 to 12 year old children in the US and Canada were recruited by an international internet research polling firm (https:IItoday.yougov.com) to complete a 15 minute online survey. Inclusion criteria were being a parent or primary guardian of a 5 to 12 year old child. Exclusion criteria included having a child with a health problem that severely restricted the types of food he/she is able to eat. Parents were sampled to yield an equal number of parents with children in the 5 to 8 year old and 9 to 12 year old age ranges and within each of these groups, to represent the ethnic diversity of each country. Further, among each ethnic group, an equal number of parents were recruited from high/moderate and low socio-economic status 
204 Canadian Census data (DeNavas-Walt, Proctor, \& Smith, 2013; Government of Canada, ). A low

205 socio-economic status was determined to be below the $40^{\text {th }}$ percentile, a moderate socio-

206 economic status was determined to be between the $40^{\text {th }}$ and $80^{\text {th }}$ percentile, and a high socio-

207 economic status was determined to be greater than the $80^{\text {th }}$ percentile for household income with 208 adjustments made for single parent households. If parents reported having children in both age 209 categories, a child within one of the age ranges was randomly selected and the parent was 210 instructed to answer survey questions based on that particular child. All participants completed 211 an online consent form. Participants were awarded 2000 points on the YouGov site for 212 completing the survey which they could use to redeem for cash or gift cards $(<\$ 5$ USD in 213 monetary value).

\section{Food Parenting Practices Assessment}

Six open-ended survey questions asked about nutrition parenting practices: 1) What sorts

221 from eating healthy? 5) If your child does not want to eat the things you want him/her to eat, 222 what do you do or say to your child? and 6) Is there anything else that you do to raise your child 223 to value healthy eating as he/she grows? Please include things you do, or have done in the past. 
226 Based on the length of responses during pilot testing, the online survey allowed parents to

227 provide ten possible answers to each open-ended question and each answer was limited to 160

228 characters to encourage responses that included no more than one idea/concept. In addition,

229 parents were prompted to be as descriptive as possible if they provided only very short answers

230 (<50 characters per question).

231 Coding

232

247 provided by individual parents were removed. 


\section{Comparing food parenting practice concepts between published literature and parent} responses

Concepts emphasized by parents were compared to those from the literature to assess the extent to which the food parenting practices reported by parents were represented in the 252 published instruments. Due to the large number of primary food parenting practice categories 253 derived from both datasets, the initial 19 food parenting practice category codes were further 254 collapsed into seven broad categories (based on commonalities) for the subsequent comparative 255 analyses (Table 1). Scale items and parent responses originally coded to the child-control 256 category were split between two broad categories; the child control items related to 257 permissiveness were grouped into "Control" whereas those pertaining to self-regulation were 258 grouped into "Autonomy Promotion."

To compare differences between US and Canadian parent responses, responses were weighted to reflect the total number of parents in each subgroup. Each parent response was weighted by dividing each response by the corresponding total number of responses according to country (US $n=1137$; Canada $n=848$ ) and multiplying by the corresponding total number of parents (US n=74; Canada n=61). A corrected Pearson chi-square (converted to an F-statistic due to the weighting) was used to assess response differences by country. A similar procedure was used to compare differences between parent responses and literature item categories. Parent responses were weighted by dividing each response by the total number of parent responses $(n=1985)$ and multiplying by the total number of parents $(n=135)$. Literature items were weighted by dividing each item by the total number of items $(n=1392)$ and multiplying by the total number of measures $(n=79)$. A corrected Pearson chi-square compared whether parents emphasized the same items as those reported in the literature. 


\section{RESULTS}

\section{Identifying published food parenting practice scales and unique concepts}

A total of 124 articles were identified from previously published systematic reviews, 39

275 articles from De Lauzon-Guillain et al. (de Lauzon-Guillain et al., 2012) and 85 articles from

276 Vaughn et al. (A. Vaughn et al., 2013). After removing duplicates there were 109 unique scales.

277 Fifteen additional articles were excluded based on the inclusion/exclusion criteria and 10 were

278 excluded because the items were not available, leaving 84 articles for data extraction (Figure 1).

279 The additional systematic review contributed eight articles into the database (Chan, Magarey, \& 280 Daniels, 2011; Dickin, Lent, Lu, Sequeira, \& Dollahite, 2012; Gubbels et al., 2011; Jensen et al., 281 2012; Kroon Van Diest \& Tylka, 2010; Lee, Conklin, \& Bordi, 2012; Monge-Rojas et al., 2010; 282 Puhl \& Schwartz, 2003). The reference lists of retrieved articles revealed three additions, which 283 included two relevant articles (O'Connor, Watson et al., 2010; Robinson, Kiernan, Matheson, \& 284 Haydel, 2001) and an unpublished report (M.A. Horodynski, personal communication, March 285 11, 2013). An assessment of PA related parenting practice instruments identified seven 286 additional measures also containing nutrition items (Johnson, Welk, Saint-Maurice, \& Ihmels, 287 2012; Lehto, Ray, \& Roos, 2012; Rodenburg, Oenema, Kremers, \& van de Mheen, 2013; Sallis, 288 Grossman, Pinski, Patterson, \& Nader, 1987; Singh et al., 2012; Taylor, Wilson, Slater, \& Mohr, 289 2011; Williams \& Mummery, 2011).

Of the resulting 102 articles (and 1957 items), 79 articles (and 1821 items) were retained 291 following the removal of articles that provided only supplemental validity of food parenting 292 practice and articles that were coded as Attitudes and/or Other only (see Appendix 1 for 293 references and study details of retained articles). After removal of items coded as "attitudes" or 
295 from published instruments consisted of 1392 items. Each item was coded into one of 19 food

296 parenting practice category codes independent of their original factor structure in order to

297 consolidate similar items. Following the consolidation cycles, these published items were 298 reduced to 231 representative food parenting concepts.

299 Parent reports of food parenting practice to supplement published items

300 A total of 74 US parents and 61 Canadian parents completed the semi-qualitative survey 301 to assess food parenting practices they reported using related to their children's eating behaviors. 302 US and Canadian samples were similar by family income, marital status, and gender of surveyed 303 parent, but (consistent with our a priori stratified recruitment procedures) ethnicity varied by 304 country (Table 2). The parents provided 2,389 responses, which resulted in identification of 3051,985 unique food parenting practices after splitting responses that mentioned multiple food 306 items, removing attitudes (3), non-parenting concepts (89), responses with insufficient 307 information (193), and duplicates (255). Coding these food parenting practices into the 308 categories used for the published literature resulted in 194 different food parenting concepts 309 reported by the parents.

\section{Comparing parent reported food parenting practice to those represented in published} scales

There were no significant differences of reported food parenting practice concepts 316 between Canadian and US parents $[\mathrm{F}(5,9920)=1.61 ; \mathrm{p}=0.15]$ (Figure 2); as a result the samples 
317 were combined for the remainder of the analyses. Via the semi-structured interviews, parents 318 reported 31 food parenting practice concepts that were not included in published food parenting 319 scales, resulting in a total of 262 unique food parenting practices concepts identified. Of those, $32026 \%$ were exclusive to previous literature, $12 \%$ were exclusive to parent responses, and $62 \%$ 321 were represented in both (Figure 3). Concepts identified by parents and not represented in 322 published scales were primarily coded in the 'Control', 'Behavioral and Educational', and 323 'Structure of Food Environment' broad categories (Table 3).

324

325

326

Figures 2 and 3, and Table 3 Here

Significant differences were detected when comparing the weighted proportion of unique food parenting practice concepts reported by parents to those published in the literature $[\mathrm{F}(6$, 20234) $=25.2 ; \mathrm{p}<0.001]$ (Figure 4). Food parenting practices related to 'Structure of Food Environment' (i.e. "I balance all food groups in my child's meals and snacks"), and 'Behavioral and Educational' (i.e. "I teach my child about how much to eat based on their level of activity") were emphasized by a larger proportion of parent responses than published scales. In contrast, practices related to 'Consistency of Feeding Environment' (e.g. "My child is offered three meals every day”) were more represented among literature items than parent statements. 'Emotional Regulation' practices were not reported by surveyed parents. A descriptive comparison of the parent responses and published items (unweighted) coded according to the initial 19 food parenting practice category codes listed in Table 1 can be found in Appendix 2.

\section{Discussion}


A systematic identification of published food parenting practice scales found a large

number of scales that have been developed and are in use for children 2-16 years old. The initial

1392 items from 79 published scales were reduced to 231 representative food parenting practices via a winnowing procedure (DeWalt et al., 2007). Despite the large number of available items, semi-qualitative input from US and Canadian parents revealed 31 (12\% of total) representative food parenting concepts not covered by existing scales. These were added to the item bank to supplement the food parenting practice concepts already published.

When comparing what parents emphasize doing to what is emphasized in the literature, differences emerged. Items grouped under 'Structure of the Environment' and 'Behavioral and Education' were highlighted more often by parents than in the literature, while "Consistency of the Feeding Environment' and 'Emotion Regulation' were emphasized more in the literature than by parents. It is possible that concepts emphasized in the literature may still be important in influencing children's behaviors, despite parents not emphasizing them. Parents may not be aware of doing them or may not associate those practices to influencing children's eating habits. For example, parents may not link giving a food treat (e.g. ice-cream) to help soothe an upset child as influencing the child's eating behaviors (an example of Emotion Regulation). However, emotional overeating among children has been associated with higher weight (Webber, Hill, Saxton, Van jaarsveld, \& Wardle, 2009), suggesting that parenting practices that promote such behaviors are likely important. It is also possible that some difference emerged because the literature review included scales intended for parents with children 2-16 years old, while the semi-qualitative responses were from parents with children 5-12 years old. However, developing an item bank that covers both concepts that scientists have identified as important and those practiced by parents is critical to having a comprehensive list of food parenting practices. We 
elected to be broad in our literature search of food parenting practice instruments in order to not miss important concepts. The final list of food parenting practices can be reduced in subsequent

steps by eliminating those concepts and items that do not describe a latent construct, or those that contain multiple concepts, or are not predictive of children's eating behaviors or weight status.

For the purpose of developing the food parenting practice item bank, we used a coding procedure to reduce and categorize over three thousand published or parent reported items into similar categories. This coding framework was not intended to be a final conceptual framework for food parenting, but a tool for our group to process the available data. We instead refer the reader to a content framework for food parenting developed by a group of experts in parenting and feeding that is more comprehensive and can inform studies in the future (A. Vaughn et al., 2015).

This study included a systematic approach to identify published food parenting scales, develop a databank of items with sample and psychometric information linked from published studies, and supplemented the published items with additional food parenting practice concepts reported by parents. Limitations include only using scales published in English, only querying parents from the US and Canada for supplemental food parenting concepts; limiting the parent responses to parents of 5-12 year old children, which overlapped but did not exactly correspond to the child age of the literature; and reducing the items into representative concepts to make the next steps more manageable. This reduction of items into representative concepts potentially loses some nuanced differences in items that could be important for understanding how parents interact with their children around food.

The next step of this item banking project, involves inviting a panel of food parenting experts to review the reduced number of food parenting practices and sort the concepts into 
dimensions based on their theoretical understanding of food parenting. This sorting will allow us to uncover the underlining conceptual dimensions of a food parenting practice framework by using concept mapping (Burke et al., 2005; Trochim, 1989), a non-parametric multidimensional scaling analysis to visually synthesize and organize the concepts into dimensions. This will help provide a conceptual framework for food parenting practice from which we can ensure we have appropriate items to cover all relevant constructs. The psychometrics of the resulting food parenting practice scales will next be assessed with data collected from a new sample of parents using traditional psychometric analysis, such as internal reliabilities and confirmatory factor analysis, as well as advanced analytical methods such as item response modeling. The ultimate goal is to develop an item bank of calibrated food parenting practice available for researchers such that they can select those relevant for their particular study, while allowing comparison across other studies. Our future aim is for the IRM calibrated item bank to be a platform for using Computerized Adaptive Testing to allow scientists to select relevant items for a given study, while maintaining the ability to compare results across studies; and reducing participant burden(Mâsse et al., 2006).

\section{Acknowledgements}

The project described was supported by award number 20R06534 from the Canadian Institute of Health Research (CIHR); LCM received salary support from the Chid \& Family Research Institute (CFRI); AWW received post-doctoral support from CIHR; and AT received post-doctoral support from CFRI and the Michael Smith Foundation for Health Research.

This work is also a publication of the US Department of Agriculture (USDA/ARS) Children's Nutrition Research Center, Department of Pediatrics, BCM funded in part by the 
409 USDA/ARS (Cooperative Agreement 6250-51000). The contents of this publication do not

7410 necessarily reflect the views or policies of the USDA, nor does mention of organizations imply

8

411 endorsement from the US government. 
416 Table 1. Primary and collapsed coding categories of food parenting practices.

\section{Primary food parenting practice Collapsed dimensions for dimension codes analyses}

Restriction

Pressure to eat

Covert control

Expressing negative emotions/reactions

Rewards/discipline

Coercive control

Redirection

Child control (permissiveness/selfregulation

Child engagement

Autonomy support

Food availability/accessibility

Food preparation

Parental encouragement to eat

Expressing positive control/reactions

Monitoring

Feeding/meal environment

Modeling

Teach/reason

Emotional feeding/regulation

Attitudes

Other

*Child control items related to permissiveness were grouped into "Control" whereas self-
Control

Autonomy promotion

Structure of food environment

Responsiveness

Consistency of feeding environment

Behavioral and educational

Emotion regulation

Dropped

Dropped 


\begin{tabular}{|c|c|c|c|c|}
\hline \multicolumn{5}{|c|}{ Table 2. Demographics of parent sample surveyed } \\
\hline Description & & US (N=74) & & Canada $(\mathrm{N}=61)$ \\
\hline Income (below median) & & $54 \%$ & & $57 \%$ \\
\hline \multirow{4}{*}{ Ethnicity } & White & $47 \%$ & White & $49 \%$ \\
\hline & Black & $17 \%$ & East/Southeast Asian & $20 \%$ \\
\hline & Hispanic & $18 \%$ & South and West Asian & $21 \%$ \\
\hline & Other/Asian & $18 \%$ & Other & $10 \%$ \\
\hline Sex of parent - female & & $59 \%$ & & $62 \%$ \\
\hline $\begin{array}{l}\text { Marital status - } \\
\text { married/common-law }\end{array}$ & & $74 \%$ & & $82 \%$ \\
\hline
\end{tabular}


2421 Table 3. Unique food parenting practice concepts from parent reports, not represented in published literature.

\section{Collapsed food parenting} practice category

\begin{tabular}{|l|l|}
\hline Control & Child control \\
\hline Control & Child control \\
\hline Control & Child control \\
\hline Control & Child control \\
\hline Control & Parental control \\
\hline Control & Parental control \\
\hline Control & Parental control \\
\hline Control & Parental control \\
\hline Control & Pressure to eat \\
\hline Control & Pressure to eat \\
\hline Control & Restriction \\
\hline Control & Rewards/discipline \\
\hline Autonomy promotion & Autonomy support \\
\hline Autonomy promotion & Autonomy support \\
\hline Autonomy promotion & Autonomy support \\
\hline Autonomy promotion & Autonomy support \\
\hline Structure of food environment & Food accessibility \& availability \\
\hline Structure of food environment & Food accessibility \& availability \\
\hline Structure of food environment & Food accessibility \& availability \\
\hline Structure of food environment & Food accessibility \& availability \\
\hline Structure of food environment & Food accessibility \& availability \\
\hline Structure of food environment & Food preparation \\
\hline Structure of food environment & Food preparation \\
\hline Responsiveness & Parental encouragement to eat \\
\hline Responsiveness & Parental encouragement to eat \\
\hline Behavioral and educational & Modeling \\
\hline Behavioral and educational & Modeling \\
\hline Behavioral and educational & Teach/reason \\
\hline Behavioral and educational & Teach/reason \\
\hline Behavioral and educational & Teach/reason \\
\hline Behavioral and educational & Teach/reason \\
\hline Behavioral and educational & Teach/reason \\
\hline & \\
\hline
\end{tabular}

\section{Most Representative Food Parenting Concept}

I allow my child to eat unhealthy food when we are away from home and on the go (e.g. doing errands, driving to practices, at the movie theatre). I allow my child to eat unhealthy food when we are on vacation/traveling. I allow my child to eat/drink [unhealthy food type] if s/he buys it. I remind/encourage my child to stop eating when s/he feels full.

I make my child include fruits and/or vegetables on his/her plate when we are eating away from home.

I make sure my child eats his/her fruits or vegetables first at mealtimes or snacks. I use scare tactics to discourage my child from eating unhealthy foods.

If my child eats junk food, s/he must also include something healthy. I tell my child that there are starving children around the world to get my child to eat all the food on his/her plate. If my child does not want to finish his/her meal, I make him/her eat it later. I encourage my child to control his/her portion by sharing unhealthy foods/drinks. I use fruits and vegetables as a reward. I ask my child to suggest healthy food alternatives. I try to understand why my child does not want to eat certain foods. If I allow my child an unhealthy meal/snack the next meal snack must be healthy. I ask my child to suggest healthy food alternatives.

I balance all food groups in my child's meals and snacks.

I provide my child with more healthy options than unhealthy options. I regularly serve dessert.

I serve water at meal times and snacks

I've consistently given fruits and vegetables to my child since he/she was little.

I do not have the time and/or energy to prepare meals from scratch. I prepare food in a variety of ways for my child.

I encourage my child to drink water when s/he feels hungry.

I encourage my child to eat [vegetables] by challenging him/her to eat it. My child sees me skipping meals.

I tell my child not to eat/drink [unhealthy food type], but do so myself.

I incorporate fruits and vegetables in educational activities or games to teach my child about healthy eating.

I read food labels with my child to go over nutrition facts of different foods.

I teach my child about how much to eat based on their level of activity.

I tell my child that eating [food type] will make him/her feel better about him/herself. I watch shows and read books with my child about healthy eating. 
Figure 1. Flow chart process for identifying published food parenting practice instruments and

8

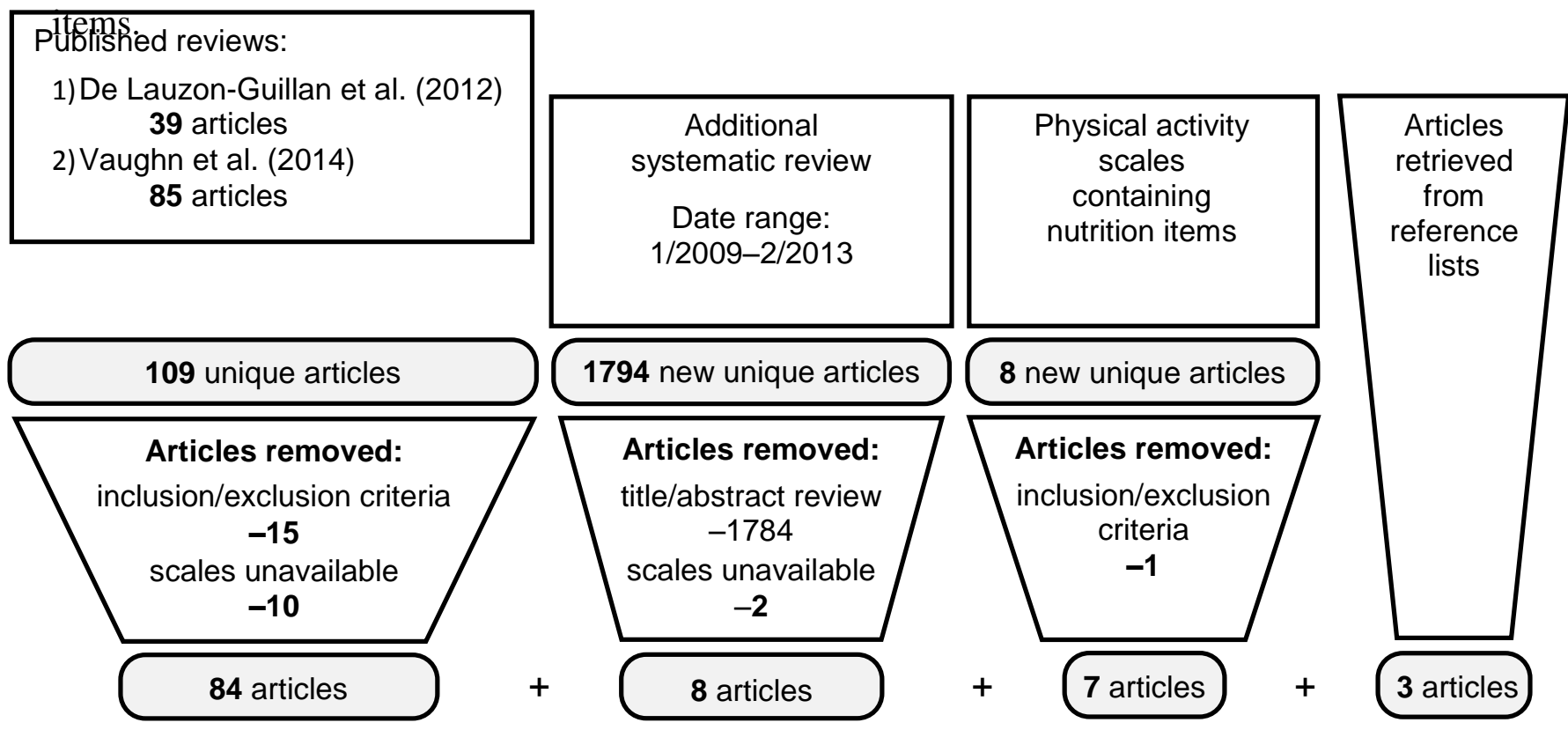

\section{Total articles extracted}

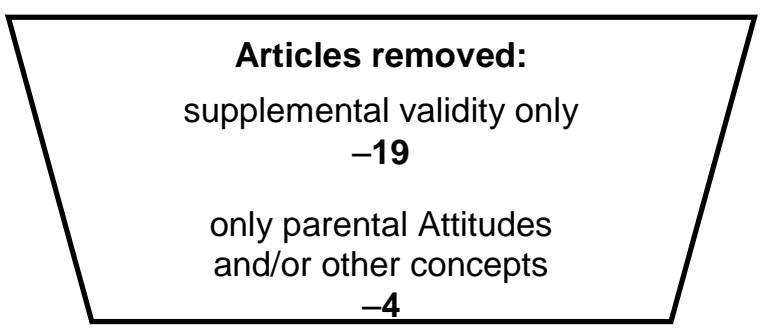

79 articles retained / 1821 items

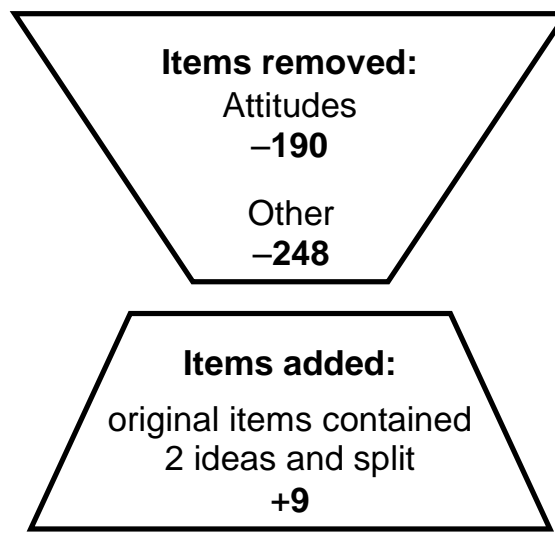

1392 items/food parenting practice item bank

Removed duplicates and collapsed similar items 
425 Figure 2. Percentage of food parenting practices identified by parents for each collapsed

426 category by country.

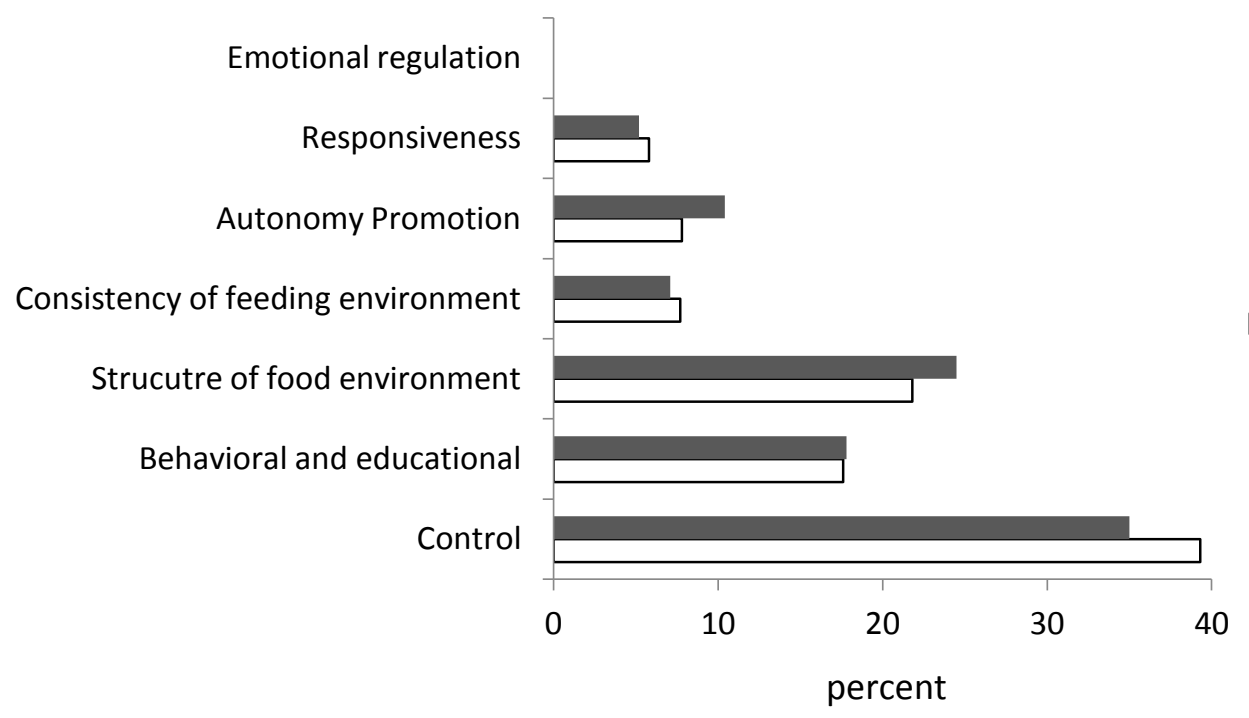

429 Legend: No significant differences were found via corrected Pearson chi square between Canada 430 and US parents overall, $\mathrm{F}(5,9920)=1.60 ; \mathrm{p}=0.15$.

Canada $(\mathrm{N}=61)$ $\square$ US (N=74) 
4432 Figure 3. Proportion of unique food parenting practices identified in literature and by parents

$7433 \quad(\mathrm{~N}=262)$.

8 
441 Legend: Overall significant differences found via corrected Pearson chi square between items 442 emphasized by parents surveyed compared to those reported in the literature, $F(6,20234)=25.2$; $443 \mathrm{p}<0.001$.

Figure 4. Percentage of unique food parenting practice concepts for each broadly collapsed category by parents and published scales.

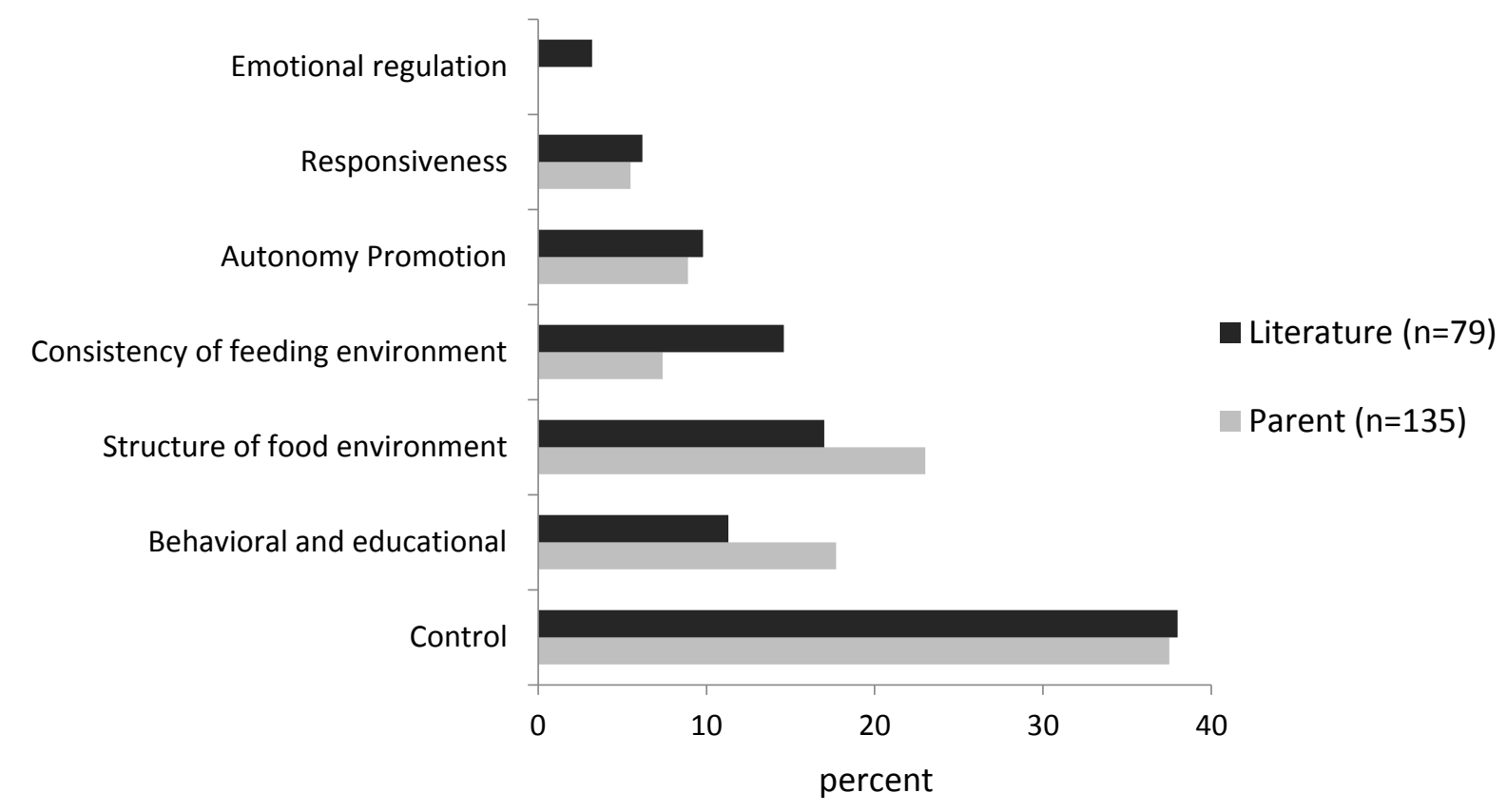

(1)

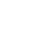

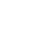

(1)

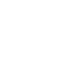

(1)

.

4


448 Barlow, S. E. (2007). Expert committee recommendations regarding the prevention, assessment, 449 and treatment of child and adolescent overweight and obesity: Summary report. Pediatrics, $450 \quad$ 120(Supp14), S164-S192.

451 Baughcum, A. E., Powers, S. W., Johnson, S. B., Chamberlin, L. A., Deeks, C. M., Jain, A., et al. 452 (2001). Maternal feeding practices and beliefs and their relationships to overweight in early

Chan, L., Magarey, A. M., \& Daniels, L. A. (2011). Maternal feeding practices and feeding behaviors of Australian children aged 12-36 months. Maternal and Child Health Journal, 15(8), 1363-1371.

Daniels, S., Arnett, D., Eckel, R., Gidding, S., Hayma, L., Kumanyika, S., et al. (2005). Overweight in children and adolescents: Pathophysiology, consequences, prevention, and treatment; AHA scientific statement. Circulation, 111, 1999-2012.

Darling, N., \& Steinberg, L. (1993). Parenting style as context: An integrative model. Psychological Bulletin, 113(3), 487-496.

de Lauzon-Guillain, B., Oliveira, A., Charles, M., Grammatikaki, E., Jones, L., Riqui, N., et al. (2012). A review of methods to assess parental feeding practices and preschool children's 
eating behaviors: The need for further development of tools. J Acad Nutr Diet, 112(10), 1578-1602.

DeNavas-Walt, C., Proctor, B., \& Smith, J. (2013). Income, poverty, and health insurance coverage in the united states: 2012: Current population reports. United States Census Bureau.,

DeWalt, D., Rothrock, N., Yount, S., \& Stone, A. (2007). Evaluation of item candidates: The PROMIS qualitative item review. Med Care, 45, S12-S21.

474 Dickin, K., Lent, M., Lu, A. H., Sequeira, J., \& Dollahite, J. (2012). Developing a measure of 475 behavior change in a program to help low-income parents prevent unhealthful weight gain in 476 children. J Nutr Educ Behav, 44(1), 12-21.

477 Garriguet D. (2004). Overview of Canadians' eating habits No. Catalogue no 82-620-MIE)

478 Government of Canada. Statistics Canada. table 111-0009 - family characteristics, summary, 479 annual (number unless otherwise noted), CANSIM (database). Retrieved December 10, $480 \quad 2015$, from http://www5.statcan.gc.ca/cansim/a26?lang=eng\&id=1110009

481 Gubbels, J., Kremers, S., Stafleu, A., de Vries, A., Goldbohm, A., Dagnelie, P., et al. (2011). 482 Association between parenting practices and children's dietary inkate, activity behavior, and

485 Guenther, P. M., Dodd, K. W., Reedy, J., \& Krebs-Smith, S. M. (2006). Most Americans eat 486 much less than recommended amounts of fruits and vegetables. Journal of the American 487 Dietetic Association, 106(9), 1371-1379. 
Harris, P. A., Taylor, R., Thielke, R., Payne, J., Gonzalez, N., \& Conde, J. G. (2009). Research electronic data capture (REDCap)--a metadata-driven methodology and workflow process for providing translational research informatics support. Journal of Biomedical Informatics, 42(2), 377-381.

Hendy, H. M., Williams, K. E., Camise, T. S., Eckman, N., \& Hedemann, A. (2009). The parent mealtime action scale (PMAS). development and association with children's diet and weight. Appetite, 52(2), 328-339.

Hughes, S. O., Anderson, C. B., Power, T. G., Micheli, N., Jaramillo, S., \& Nicklas, T. A. (2006). Measuring feeding in low-income African-American and Hispanic parents. Appetite, 46(2), 215-223.

Hughes, S. O., Power, T. G., Orlet Fisher, J., Mueller, S., \& Nicklas, T. A. (2005). Revisiting a neglected construct: Parenting styles in a child-feeding context. Appetite, 44(1), 83-92.

Jensen, J. D., Bere, E., De Bourdeaudhuij, I., Jan, N., Maes, L., Manios, Y., et al. (2012). Microlevel economic factors and incentives in children's energy balance related behaviours findings from the ENERGY European cross-section questionnaire survey. The International Journal of Behavioral Nutrition and Physical Activity, 9, 136-5868-9-136.

Johnson, R., Welk, G., Saint-Maurice, P. F., \& Ihmels, M. (2012). Parenting styles and home obesogenic environments. International Journal of Environmental Research and Public Health, 9(4), 1411-1426.

Kirkpatrick, S., Dodd, K., Reedy, J., \& Kreb-Smith, S. (2012). Income and race/ethnicity are associated with adherence to food-based dietary guidance among US adults and children. $J$ Acas Nutr Diet, 112(5), 624-635. 
Kroon Van Diest, A. M., \& Tylka, T. L. (2010). The caregiver eating messages scale:

Development and psychometric investigation. Body Image, 7(4), 317-326.

Lee, K., Conklin, M., \& Bordi, P. (2012). Predicting caregiver behaviors toward restaurants providing healthful children's menus with nutrition information: A pilot study. Topics in Clinical Nutrition, 27(2), 95-104. Retrieved from SCOPUS database.

Lehto, R., Ray, C., \& Roos, E. (2012). Longitudinal associations between family characteristics and measures of childhood obesity. International Journal of Public Health, 57(3), 495-503. doi:10.1007/s00038-011-0281-5; 10.1007/s00038-011-0281-5

518 Masse, L., \& Watts, A. (2013). Stimulating innovations in the measurement of parenting 519 constructs. Childhood Obesity, 9(S1), S5-S13.

520 Mâsse, L., Wilson, M., Baranowski, T., \& Nebeling, L. (2006). Improving psychometric 521 methods in health education and health behavior research. Health Education Research, $522 \quad 21($ Suppl 1), i1-i3.

523 Mokkink, L., Terwee, C., Patrick, D., Alonso, J., Strat-ford, P., Knol, D., et al. (2010)

524 International consensus on taxonomy, terminology, and definitions of measurement 525 properties for health-related patient reported outcomes: Results of the COSMIN study. $J$ $526 \quad$ Clin Epidemiol, 63(7), 737-45

527 Monge-Rojas, R., Smith-Castro, V., Colon-Ramos, U., Garita-Arce, C., Sanchez-Lopez, M., \& 528 Chinnock, A. (2010). Parental feeding styles and adolescents' healthy eating habits. structure 529 and correlates of a Costa Rican questionnaire. Appetite, 55(2), 253-262. 
Murashima, M., Hoerr, S., Hughes, S., \& Kaplowitz, S. (2011). Confirmatory factor analysis of a questionnaire measuring control in parental feeding practices in mothers of head start children. Appetite, 56(3), 594-601.

533 O’Connor, T., Hughes, S., Watson, K., Baranowski, T., Nicklas, T., Fisher, J., et al. (2010).

534 Parenting practices are associated with fruit and vegetable consumption in preschool $535 \quad$ children. Public Health Nutrition, 13(1), 91-101.

536 O'Connor, T., Watson, K., Hughes, S., Beltran, A., Hingle, M., Baranowski, J., et al. (2010).

537 Health professionals' and dietetics professionals' perceived effectiveness of fruit and 538 vegetable parenting practices across six countries. Journal of the American Dietetic $539 \quad$ Association, 110(7), 1065-1071.

540 Ogata, B., \& Hayes, D. (2014). Position of the academy of nutrition and dietetics: Nutrition 541 guidance for healthy children ages 2 to 11 years. J Acad Nutr Diet, 114(8), 1257-1276.

542 Puhl, R. M., \& Schwartz, M. B. (2003). If you are good you can have a cookie: How memories 543 of childhood food rules link to adult eating behaviors. Eating Behaviors, 4(3), 283-293.

544 Revicki, D., \& Cella, D. (1997). Health status assessment for the twenty-first century: Item 545 response theory, item banking and computer adaptive testing. Qual Life Res, 6(595), 600.

546 Robinson, T. N., Kiernan, M., Matheson, D. M., \& Haydel, K. F. (2001). Is parental control over 547 children's eating associated with childhood obesity? results from a population-based sample $548 \quad$ of third graders. Obesity Research, 9(5), 306-312. 
Rodenburg, G., Oenema, A., Kremers, S. P., \& van de Mheen, D. (2013). Clustering of diet- and activity-related parenting practices: Cross-sectional findings of the INPACT study. The International Journal of Behavioral Nutrition and Physical Activity, 10, 36-5868-10-36.

552 Sallis, J. F., Grossman, R. M., Pinski, R. B., Patterson, T. L., \& Nader, P. R. (1987). The 553 development of scales to measure social support for diet and exercise behaviors. Preventive $554 \quad$ Medicine, 16(6), 825-836.

555 Singh, A. S., Chinapaw, M. J., Uijtdewilligen, L., Vik, F. N., van Lippevelde, W., Fernandez556 Alvira, J. M., et al. (2012). Test-retest reliability and construct validity of the ENERGYparent questionnaire on parenting practices, energy balance-related behaviours and their potential behavioural determinants: The ENERGY-project. BMC Research Notes, 5, 4340500-5-434.

Taylor, A., Wilson, C., Slater, A., \& Mohr, P. (2011). Parent- and child-reported parenting. associations with child weight-related outcomes. Appetite, 57(3), 700-706.

Trochim, W. (1989). An introduction to concept mapping for program planning and evaluation. Evaluation and program planning (pp. 1-16)

US Department of Health and Human Services, US Department of Agriculture, Dietary Advisory Guidelines Committee. (2005). Dietary guidelines for Americans 2005. Retrieved 8/23, 2005, from http://www.health.gov/dietaryguidelines/dga2005/document/default.htm

Vaughn, A., Tabak, R., Bryant, M., \& Ward, D. (2013). Measuring parent food practices: A systematic review of existing measures and examination of instruments. Int J Behav Nutr Phys Act, 10(61) 
2

3

4

5

7

8

$572 \quad$ Reviews, 74(2) 98-117

573 Wardle, J., Sanderson, S., Guthrie, C. A., Rapoport, L., \& Plomin, R. (2002). Parental feeding $574 \quad$ style and the inter-generational transmission of obesity risk. Obesity Research, 10(6), 453-

575462

576 Webber, L., Hill, C., Saxton, J., Van jaarsveld, C., \& Wardle, J. (2009). Eating behavior and 577 578 579 580 581 weight status in children. Int J Obes (London), 33(1), 21-28.

Williams, S. L., \& Mummery, W. K. (2011). Links between adolescent physical activity, body mass index, and adolescent and parent characteristics. Health Education \& Behavior : The Official Publication of the Society for Public Health Education, 38(5), 510-520. 